\section{Effect of Intermediate Flush Using Different Devices to Prevent Chemical Smear Layer Formation}

Camilla Corrêa Silva1, Vivian Maria Durange Ferreira', Gustavo De-Deus², Daniel Rodrigo Herrera3 ${ }^{3}$ Maíra do Prado ${ }^{3}$, Emmanuel João Nogueira Leal da Silva ${ }^{1}$

\begin{abstract}
This study compared the effect of intermediate flush with distilled water delivered by conventional irrigation, EndoVac microcannula or Self-Adjusting File (SAF) system in the prevention of chemical smear layer (CSL) formation. Thirty human premolars were used. Canals were prepared with Reciproc system and 5.25\% NaOCl. After chemomechanical preparation, samples were divided in 3 groups $(n=10)$ according to the intermediate irrigation protocol with distilled water using: conventional irrigation, EndoVac microcannula or SAF. A final flush with $2 \%$ chlorhexidine solution was used and scanning electron microscopy was performed to assess protocol effectiveness. Two calibrated evaluators attributed scores according the presence or absence of CSL on the surface of the root canal walls at the coronal, middle and apical thirds, as follows: (1) no

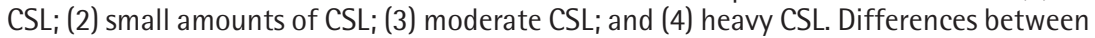
protocols were analyzed with Kruskal-Wallis and Mann-Whitney U tests. Friedman and Wilcoxon signed rank tests were used for comparison between each root canal third. SAF resulted in less formation of CSL when compared with the conventional irrigation and EndoVac microcannula $(p<0.05)$. When root canal thirds were analyzed, conventional irrigation and EndoVac groups showed less CSL formation at coronal and middle thirds in comparison to the apical third $(p<0.05)$. In SAF group, there was no difference among the thirds ( $p>0.05)$. It may be concluded that an intermediate flush of distilled water, delivered by the SAF system resulted in a better reduction of CSL formation during chemomechanical preparation.
\end{abstract}

\author{
'Department of Endodontics, \\ School of Dentistry, UNIGRANRIO \\ - Universidade do Grande Rio, \\ Duque de Caxias, RJ, Brazil \\ ${ }^{2}$ Department of Endodontics, \\ Fluminense Federal University, \\ Niterói, RJ, Brazil \\ ${ }^{3}$ Department of Endodontics, \\ Piracicaba School of Dentistry, \\ UNICAMP - Universidade Estadual \\ de Campinas, Piracicaba, SP, Brazil
}

Correspondence: Dr. Emmanuel João Nogueira Leal da Silva, Rua Herotides de Oliveira, 61/902, 24230-120, Niterói, RJ, Brasil. Tel:+55-21-8357-5757. e-mail: nogueiraemmanuel@hotmail.com

Key Words: chlorhexidine; smear layer; sodium hypochlorite.

\section{Introduction}

The success of endodontic treatment depends on cleaning, disinfection and shaping of the root canal system (1). The root canal system is anatomically complex, and mechanical instrumentation does not provide a fully prepared root canal surface (2). Also, irregularities, isthmuses and ramifications are not accessed by mechanical instruments. Therefore, different auxiliary substances have been used in association with instruments during mechanical preparation, to provide a better cleaning and disinfection (3).

Among the substances used in endodontics during chemomechanical preparation, sodium hypochlorite $(\mathrm{NaOCl})$, in different concentrations, has been the most commonly used (3). This endodontic irrigant has the ability to destroy a broad spectrum of microbes and to dissolve organic tissue; however, it is known that $\mathrm{NaOCl}$ solutions have cytotoxic effects and alter dentin microhardness, as well as the organic components of dentin, especially collagen (3).

Chlorhexidine ( $\mathrm{CHX}$ ) has been used during endodontic therapy because it is an effective antimicrobial agent which has substantivity on dentin surface (4). Additionally this substance has a positive effect in adhesion of endodontic sealers (5) and increases the longevity of resin-dentin bonds (6). Because $\mathrm{CHX}$ lacks the tissue-dissolving capabilities of the $\mathrm{NaOCl}$, it has been suggested the use of $\mathrm{CHX}$ as an additional irrigant, for intracanal medication or as a final flush (3).

In general, an irrigant is not completely flushed out from the root canal system before applying the next irrigant. As a result, endodontic irrigants routinely come into contact with each other inside the root canal (7). In this aspect, the literature shows that when $\mathrm{NaOCl}$ interacts with $\mathrm{CHX}$ inside the root canal, an orange-brown precipitate is produced. This precipitate forms a chemical smear layer (CSL) on dentin surface, occluding the dentinal tubules. This layer may affect close adaptation between root canal filling materials and the root canal walls, interfering in the seal of the root canal filling $(8,9)$. In addition, this precipitate changes the color of the tooth and is cytotoxic (10-12).

To prevent the precipitate formation, several strategies have been proposed, such as the use of intermediate solutions between the use of $\mathrm{NaOCl}$ and $\mathrm{CHX}(7,13,14)$ or techniques to remove the CSL after its formation (15). 
However, both strategies failed to prevent completely the precipitation of residues on root canal walls. It is expected that the ideal protocol uses a substance that does not react with the other used irrigants (such as distilled water) and capable to flush out previously used irrigants. Moreover, a delivery technique that allows a better dispersion of this intermediate solution throughout root canal space should be selected. Thus, the present study aimed to compare the effect of an intermediate flush of distilled water delivered using EndoVac microcannula ( Kerr Comporation, Orange, CA, USA) or Self-Adjusting File (SAF - ReDent-Nova, Ra'anana, Israel) to prevent the formation of CSL. Conventional irrigation was used as reference for comparison. The null hypothesis tested was that there are no differences in the CSL formation when different protocols were used.

\section{Materials and Methods}

The present study was approved by the Human Research Ethics Committee of Grande Rio University (UNIGRANRIO) protocol 48566215.1.0000.5283. Thirty human premolars with single straight canals, radiographically confirmed and fully formed roots, all extracted for orthodontic reasons, were selected for this study. They were stored at $4{ }^{\circ} \mathrm{C}$ in $0.2 \%$ thymol solution. Prior to the experiments, all teeth were examined visually and radiographically to exclude specimens with resorption, previous root canal treatment or canal calcification.

\section{Sample preparation}

The apexes were sealed with hot glue and embedded in polyvinyl siloxane to simulate the effect of apical gas entrapment in a closed canal system. After access cavity preparation, the working length $(\mathrm{WL})$ was determined by passing a size $10 \mathrm{~K}$-file through the apical foramen and withdrawing it $1.0 \mathrm{~mm}$. A glide path was established by scouting a size $15 \mathrm{~K}$-file (DentsplyMaillefer, Ballaigues, Switzerland) up to the WL.

All root canals were prepared with Reciproc system (VDW, Munich, Germany). Instruments were driven with the VDW Silver motor according to manufacturer's instructions and a single experienced operator performed all preparations. Reciproc instrument R25 (25/0.08) was introduced into the canal until resistance was felt and then activated in reciprocating motion. The instrument was moved in an apical direction using an in-and-out pecking motion of about $3 \mathrm{~mm}$ in amplitude with a light apical pressure. After 3 pecking motions, the instrument was removed from the canal, and its flutes were cleaned off. This procedure was performed until the instrument reached the WL. Afterwards, the Reciproc R40 instrument $(40 / 0.06)$ was used with the same protocol.

After each file insertion, root canals were irrigated with $5 \mathrm{~mL}$ of $5.25 \% \mathrm{NaOCl}$ for 2 min delivered by the VATEA peristaltic pump (ReDent-Nova) at a $2.5-\mathrm{mL} / \mathrm{min}$ rate connected to a 30-G Endo-Eze Tip (Ultradent Products Inc, South Jordan, UT, USA) inserted up to $2 \mathrm{~mm}$ from the apical foramen. Aspiration was performed with a SurgiTip (Ultradent Products Inc.) attached to a high speed suction pump. A total volume of $30 \mathrm{~mL}$ of $5.25 \% \mathrm{NaOCl}$ was used per canal.

After chemomechanical preparation, teeth were randomly assigned (http://www.random.org) into 3 experimental groups $(n=10)$ according to the used intermediate flush protocol:

Conventional irrigation - The intermediate flush was made with $5 \mathrm{~mL}$ distilled water for 5 min using 30-G EndoEZE needles. The needle was inserted $1 \mathrm{~mm}$ from WL and connected to the peristaltic pump VATEA using a constant flow of irrigating solution of $1 \mathrm{~mL} / \mathrm{min}$.

SAF - The intermediate flush was performed with $5 \mathrm{~mL}$ of distilled water for $5 \mathrm{~min}$, activated with the SAF and used $0.5 \mathrm{~mm}$ from WL. The SAF was operated by usig a transline (in-and-out) vibrating handpiece (Nouvag, Samstag, Switzerland) combined with a RDT3 head (ReDent-Nova) at an $83.3 \mathrm{~Hz}$ frequency (5000 movements per minute) and a $0.4 \mathrm{~mm}$ amplitude. The SAF instrument was coupled to the handpiece and the whole was connected to the peristaltic pump with a $1 \mathrm{~mL} / \mathrm{min}$ constant flow of irrigating solution .

EndoVac - The intermediate flush was performed with $5 \mathrm{~mL}$ distilled water for $5 \mathrm{~min}$ using the microcannula (32/.02) of the EndoVac system on WL. Pulp chamber was filled with distilled water by the Endo-EZE 30-G needle connected to the peristaltic pump with a $1 \mathrm{~mL} / \mathrm{min}$ constant flow of irrigating solution .

Afterwards, the root canals were rinsed with $3 \mathrm{~mL}$ of 17\% ethylene-diamine-tetra-acetic acid (EDTA, $\mathrm{pH}=7.7$ ) delivered at a $1-\mathrm{mL} / \mathrm{min}$ rate for $3 \mathrm{~min}$ followed by a 2-min 5- $\mathrm{mL}$ rinse with 2\% CHX. At last, the root canals were dried with R40 absorbent paper points (VDW).

\section{Scanning Electron Microscopy (SEM) Analysis}

Two longitudinal grooves were prepared on both buccal and lingual surfaces by a diamond disc without penetrating the canal. The roots were then split into two halves with a hammer and chisel. Both halves were used for the study. Each specimen was dehydrated in graded series of ethanol solutions, critically point dried, mounted on stubs, goldsputtered, and then examined with a scanning electron microscope (JSM 6460 LV; JEOL, Tokyo, Japan), as described previously by do-Prado et al. (7). SEM micrographs were taken at 1000x magnification at the coronal, middle and apical thirds of the root canals. Three images were acquired 
per third, nine per tooth. One hundred and eighty SEM micrographs were evaluated per group.

SEM images were assessed two times in random order by two blinded observers at 1-week interval without knowing the previous result to score the presence or absence of CSL at the coronal, middle and apical portions as follows (Figure 1):

No CSL; Little CSL; Moderate CSL; Heavy CSL.

\section{Statistical Analysis}

Weighted coefficient kappa (Kw) was used to measure the interobserver reproducibility between observers, separately for each time period. and to measure The intraobserver reproducibility was measured by the same protocol. The differences between protocols were analyzed with Kruskal-Wallis and Mann-Whitney U tests. Friedman and Wilcoxon signed rank tests were used for comparison between each root canal third. The significance level was set at $p<0.05$. Statistical analysis was performed by the Graph-Pad software (GraphPad Inc., San Diego, CA, USA).

\section{Results}

Kappa test indicated an excellent agreement between examiners with values above 0.9 (16). Table 1 summarizes the mean ranks and median scores for CSL formation presented by each group and root third. The use of SAF resulted in less formation of CSL compared with the conventional irrigation and EndoVac $(p<0.05)$. Conventional irrigation and EndoVac groups showed less CSL formation at coronal and middle thirds in comparison to the apical third $(p<0.05)$. In the SAF group, no difference was observed among the root canal thirds $(p<0.05)$. Representative SEM micrographs of each group are shown in Figure 2.

\section{Discussion}

There is no consensus in the literature concerning the most effective protocol to avoid CSL formation using intermediate flushes. To be fully effective, the intermediate flush must reach the whole length of the root canal. Previous studies about smear layer removal have shown that the conventional irrigation provides effective cleaning
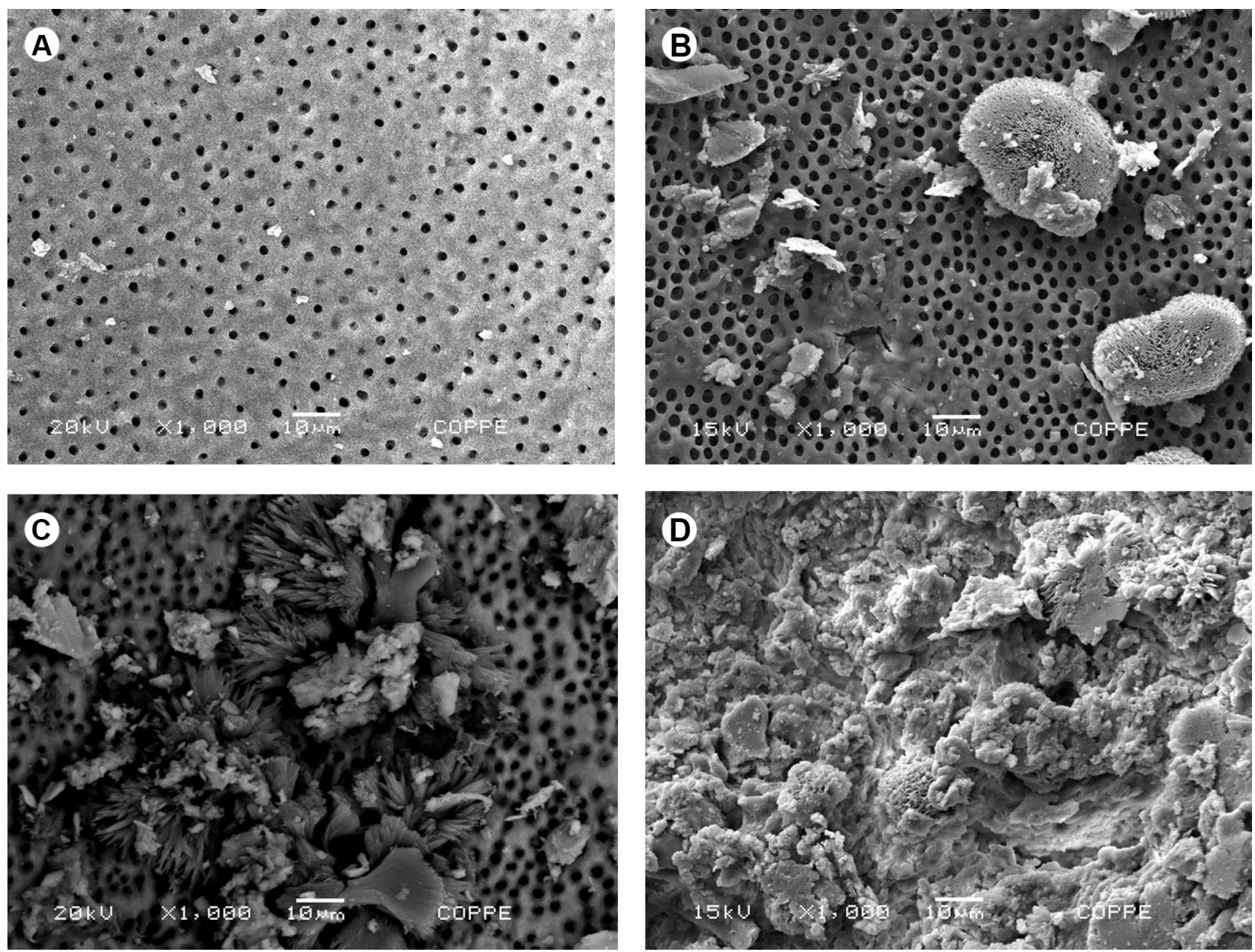

Figure 1. SEM micrographs representative of the score system: (A) no chemical smear layer; (B) small amounts of chemical smear layer; (C) moderate chemical smear layer and (D) heavy chemical smear layer. 
of the cervical and middle thirds, but this is not enough for the apical third (17). These results could be used to explain the inability of conventional irrigation to achieve the apical third effectively and prevent the CSL formation.

The present study proposed the use of an intermediate flush with distilled water delivered with EndoVac microcannula or SAF to prevent the CSL formation. The results of this study rejected the tested null hypothesis. The use of SAF produced less CSL when compared to

Table 1. Mean ranks and median scores (in parentheses) for CSL formation using the different protocols and at each root canal third

\begin{tabular}{lccc}
\hline Groups & Coronal & Middle & Apical \\
\hline Conventional irrigation & $2.55 \pm 1.00(2)^{\mathrm{A}, \mathrm{a}}$ & $2.77 \pm 0.80(2)^{\mathrm{A}, \mathrm{a}}$ & $3.00 \pm 0.81(3)^{\mathrm{A}, \mathrm{b}}$ \\
EndoVac & $2.45 \pm 0.78(2)^{\mathrm{A}, \mathrm{a}}$ & $2.64 \pm 0.90(2)^{\mathrm{A}, \mathrm{a}}$ & $2.97 \pm 0.87(3)^{\mathrm{A}, \mathrm{b}}$ \\
Self-Adjusting file & $1.90 \pm 0.75(1.5)^{\mathrm{B}, \mathrm{a}}$ & $1.90 \pm 0.58(1.5)^{\mathrm{B}, \mathrm{a}}$ & $2.09 \pm 0.71(1.5)^{\mathrm{B}, \mathrm{a}}$ \\
\hline
\end{tabular}

Different capital letters indicate significant difference within each column. Different lowercase letters indicate significant difference within each row. conventional irrigation and EndoVac groups $(p<0.05)$. The positive results of SAF can be associated with its adjustment to root canal walls, which can be translated into improved cleanlining in areas generally untouched by instruments during preparation procedures, associated with the concomitant irrigant delivery and agitation. This agrees with previous studies that showed that SAF is an excellent auxiliary tool to mechanical removal of the smear layer $(18,19)$.

Comparing the different thirds, in the conventional irrigation and EndoVac groups the coronal and middle thirds had less CSL formation than the apical third; these results may be explained by a deficient irrigation performance in the apical third and the consequent presence of $\mathrm{NaOCl}$ residues, allowing the interaction between substances and CSL formation Conventional irrigation, although performed with a side vented
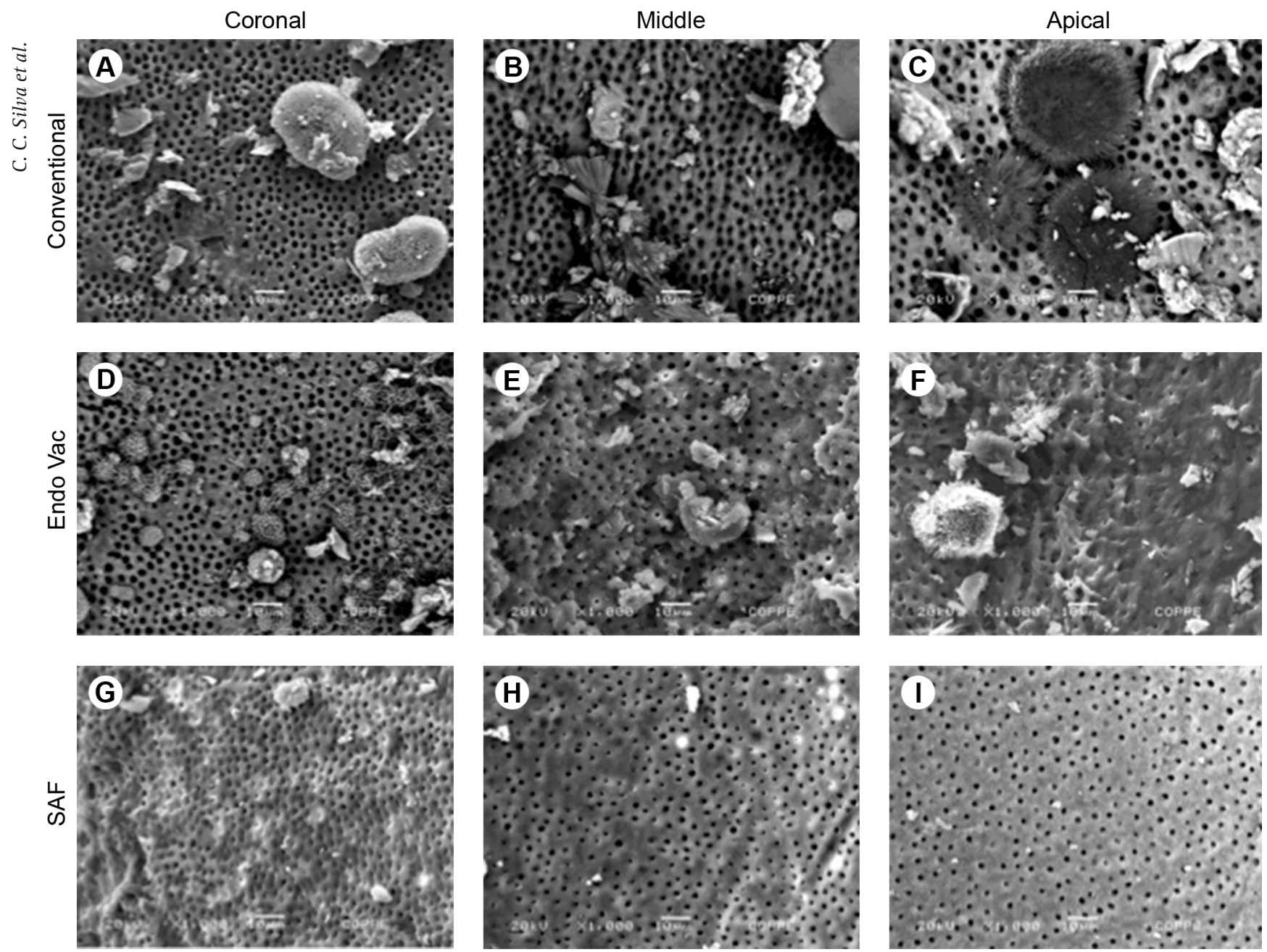

Figure 2. SEM micrographs representative of the different protocols and at each root canal third. 
needle, was performed $1 \mathrm{~mm}$ short of the WL to prevent or reduce extravasation. Siu et al. (20) demonstrated that EndoVac promotes more effective root canal cleaning than conventional irrigation, when the microcannula was used either at 1 or $3 \mathrm{~mm}$ short of WL. Since the microcannula of the EndoVac system has a close end and was proposed to reach the entire WL of root canal (21), in this study the microcannula was used on $\mathrm{WL}_{\text {; }}$ however this protocol was not able to prevent completely the CSL formation, especially in the apical third. In contrast, in SAF group no difference was observed among the root canal thirds. These results may be explained because while one irrigation protocol is basically passive, the other one presents an interplay between constant irrigant delivery and agitation allowing that $\mathrm{NaOCl}$ mixed with distilled water and diluted faster. Moreover, as previously demonstrated, SAF has the ability to touch the walls of a great part of the root canal system even at difficult areas, such as the apical third (22), and this might be an advantage of SAF compared to the other tested groups. SAF operates with an $0.4 \mathrm{~mm}$ amplitude, therefore it was not used at the WL but $0.5 \mathrm{~mm}$ from the WL to prevent that instrument operated outside root canal.

Previous studies evaluated the use of different irrigants to prevent CSL formation in the association between $\mathrm{NaOCl}$ and $\mathrm{CHX}(13,14,23)$. According to Krishnamurthy and Sudhakaran (13), when absolute alcohol, saline solution, and distilled water were used as intermediate flushes between the $\mathrm{NaOCl}$ and $\mathrm{CHX}$, only the use of absolute alcohol prevented precipitate formation. However, Magro et al. (14) observed that isopropyl alcohol, saline and distilled water failed to prevent the precipitation of residues on canal walls following the use of $\mathrm{NaOCl}$ and CHX. Do Prado et al. (7) evaluated intermediate flushes using distilled water in association with EDTA, citric acid or phosphoric acid. According to the results, authors suggested that a protocol using an intermediate application of $37 \%$ phosphoric acid solution $(1 \mathrm{~mL} \mathrm{NaOCl}$ $+10 \mathrm{~mL}$ distilled water $+1 \mathrm{~mL}$ phosphoric acid $+10 \mathrm{~mL}$ distilled water $+1 \mathrm{~mL}$ chlorhexidine solution) would not induce formation of chemical smear layer. Further studies should evaluate the effect of intermediate flush with non-conventional irrigants delivery devices associated to different intermediate chemical substances.

It is important to emphasize that in the present study final irrigation of the root canals was performed with $\mathrm{CHX}$ just after using EDTA. Rasimick et al (24) observed that the interaction between chlorhexidine digluconate and EDTA forms a precipitate. However those authors did not evaluate the morphology of this precipitate. Do Prado et al. (7) evaluated the morphology of the precipitate formed by the interaction between $\mathrm{NaOCl}$ and $\mathrm{CHX}$ using scanning electron microscopy (SEM) and evaluated chemically this precipitate using energy-dispersive X-ray spectroscopy (EDS). They observed different morphology and chemical composition between chemical and mechanical smear layer. In the present study, the authors believed that the precipitate evaluated here resulted from interaction of $\mathrm{NaOCl}$ and $\mathrm{CHX}$ due the morphology, similar to that observed in the do Prado et al study (7) regarding the chemical smear layer. Additionally, as the process to form the precipitate between $\mathrm{NaOCI} / \mathrm{CHX}$ and EDTA/CHX is different (25), its morphology also can be different. Therefore, further studies using SEM and EDS should be performed to evaluate the chemical smear layer formed due to the interaction between different irrigants like $\mathrm{CHX}$ and EDTA. It is important to emphasize that regardless the type of the formed precipitate, the present study may contribute to adoption of a protocol capable to avoid its formation.

In order to have a methodological design close to clinical situations, in the present study a closed-end canal model was used. Root canal instrumentation was performed and canals were enlarged to an apical size of a 40/0.06 file to allow adequate penetration of solutions to the apical third $(14,15)$.

Regarding the limitations of this methodological approach, most studies on smear layer analysis are performed by using conventional SEM, which means that it requires high vacuum and metalized specimen surfaces to allow visualization of the area to be evaluated. Since desiccated and metalized specimens do not allow new experimental interventions, this type of analysis allows only acquisition of post-treatment images in a single moment of the study. This model has been criticized as not allowing for longitudinal evaluations. Also, for studies of smear layer removal, root canal areas not touched by instrumentation may be erroneously scored as areas of removed smear layer and lead the researchers to mistaken conclusions by assigning maximum cleaning values to areas previously free of smear layer (19). In the present study root canal areas not touched by instrumentation did not affect the results, since chemical smear layer has a morphology different than mechanical smear layer (7) and it was formed on dentin surface.

None of the tested protocols yielded root canals completely free of CSL. Intermediate flush using distilled water associated with the Self-adjusting File was superior to conventional irrigation and Endovac system to reduce the chemical smear layer formation.

\section{Resumo}

0 presente estudo comparou o efeito da utilização de uma irrigação intermediária com água destilada usando a irrigação convencional, a microcânula EndoVac ou o sistema Self-Adjusting File (SAF) na prevenção de formação da smear-layer química (SLO). Trinta pré-molares humanos foram utilizados. Os canais foram preparados com sistema Reciproc e 
irrigados com $\mathrm{NaOCl}$ a 5,25\%. Após o preparo químico mecânico, as amostras foram divididas em 3 grupos $(n=10)$ de acordo com o protocolo de irrigação intermediária com água destilada utilizado: irrigação convencional, a microcânula EndoVac ou SAF. Utilizou-se uma lavagem final com solução de clorexidina a $2 \%$ e a microscopia electrónica de varredura foi utilizada para avaliar a eficácia dos protocolos. Dois avaliadores calibrados atribuíram escores de acordo com a presença ou ausência de SLQ nas paredes do canal radicular nos terços coronal, médio e apical, como a seguir: (1) sem SLQ; (2) pequenas quantidades de SLQ; (3) SLQ moderada e (4) muita SLQ. As diferenças entre protocolos foram analisadas com testes de Kruskal-Wallis e Mann-Whitney U. Os testes Friedman e Wilcoxon foram utilizados para comparação entre cada terço do canal radicular. SAF resultou em menor formação de SLQ quando comparado com a irrigação convencional e a microcânula EndoVac $(p<0,05)$. Quando os terços dos canais radiculares foram analisados, os grupos irrigação convencional e microcânula EndoVac apresentaram menor formação de SLO nos terços coronal e médio em relação ao terço apical $(p<0,05)$. No grupo SAF, não houve diferença entre os terços $(p>0,05)$. Dentro dos resultados do presente estudo, pode-se concluir que um fluxo intermediário de água destilada, administrado pelo sistema SAF resultou em melhor redução da formação de SLQ durante o preparo químico mecânico.

\section{References}

1. Schmidt TF, Teixeira CS, Felippe MC, Felippe WT, Pashley DH, Bortoluzzi EA. Effect of ultrasonic activation of irrigants on smear layer removal. J Endod 2015;41:1359-1363.

2. Peters OA. Current challenges and concepts in the preparation of root canal systems: a review. J Endod 2004;30:559-567.

3. Zehnder M. Root canal irrigants. J Endod 2006;32:389-398.

4. Gomes BP, Vianna ME, Zaia AA, Almeida JF, Souza-Filho FJ, Ferraz CC. Chlorhexidine in endodontics. Braz Dent J 2013;24:89-102.

5. Hashem AA, Ghoneim AG, Lutfy RA, Fouda MY. The effect of different irrigating solutions on bond strength of two root canal-filling systems. J Endod 2009;35:537-540.

6. Cecchin D, Farina AP, Giacomin M, Vidal Cde M, Carlini-Júnior B, Ferraz CC. Influence of chlorhexidine application time on the bond strength between fiber posts and dentin. J Endod 2014;40:2045-2048.

7. Do Prado M, Simão RA, Gomes BP. Evaluation of different irrigation protocols concerning the formation of chemical smear layer. Microsc Res Tech 2013;76:196-200.

8. Akisue E, Tomita VS, Gavini G, Poli de Figueiredo JA. Effect of the combination of sodium hypochlorite and chlorhexidine on dentinal permeability and scanning electron microscopy precipitate observation. J Endod 2010;36:847-850.

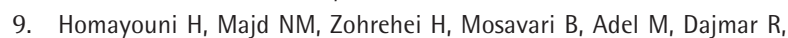
et al.. The effect of root canal irrigation with combination of sodium hypo-chlorite and chlorhexidine gluconate on the sealing ability of obturation materials. Open Dent J 2014;8:184-187.

10. Bui TB, Baumgartner JC, Mitchell JC. Evaluation of the interaction between sodium hypochlorite and chlorhexidine gluconate and its effect on root dentin. J Endod 2008;34:181-185.
11. Burkhardt-Holm P, Oulmi Y, Schroeder A, Storch V, Braunbeck T. Toxicity of 4-chloroaniline in early life stages of zebrafish (Danio rerio): II. Cytopathology and regeneration of liver and gills after prolonged exposure to waterborne 4-chloroaniline. Arch Environ Contam Toxicol 1999;37:85-102.

12. Cintra $L T$, Watanabe $\mathrm{S}$, Samuel $\mathrm{RO}$, et al.. The use of $\mathrm{NaOCl}$ in combination with $\mathrm{CHX}$ produces cytotoxic product. Clin Oral Investig 2014;18:935-940.

13. Krishnamurthy S, Sudhakaran S. Evaluation and prevention of the precipitate formed on interaction between sodium hypochlorite and chlorhexidine. J Endod 2010;36:1154-1157.

14. Magro MG, Kuga MC, Aranda-Garcia AJ, Victorino KR, Chávez-Andrade $\mathrm{GM}$, Faria $\mathrm{G}$, et al. Effectiveness of several solutions to prevent the formation of precipitate due to the interaction between sodium hypochlorite and chlorhexidine and its effect on bond strength of an epoxy-based sealer. Int Endod J 2015;48:478-483

15. Metri $M$, Hegde $S$, Dinesh $K$, Indiresha HN, Nagaraj $S$, Bhandi SH. Comparative evaluation of two final irrigation techniques for the removal of precipitate formed by the interaction between sodium hypochlorite and chlorhexidine. J Contemp Dent Pract 2015;16:850853.

16. Landis JR, Koch GG. The measurement of observer agreement for categorical data. Biometrics 1977;33:159-174.

17. Wu MK, Wesselink PR. Efficacy of three techniques in cleaning the apical portion of curved root canals. Oral Surg Oral Med Oral Pathol Oral Radiol Endod 1995;79:492-496.

18. Adigüzel O, Yigit-Özer S, Kaya S, Uysal İ, Ganidagli-Ayaz S, Akkus Z. Effectiveness of ethylenediaminetetraacetic acid (EDTA) and MTAD on debris and smear layer removal using a self-adjusting file. Oral Surg Oral Med Oral Pathol Oral Radiol Endod 2011;112:803-808.

19. De-Deus G, Reis C, Paciornik S. Critical appraisal of published smear layer-removal studies: methodological issues. Oral Surg Oral Med Oral Pathol Oral Radiol Endod 2011;112:531-543.

20. Siu C, Baumgartner JC. Comparison of the debridement efficacy of the EndoVac irrigation system and conventional needle root canal irrigation in vivo. J Endod 2010;36:1782-1785.

21. Nielsen BA, Craig Baumgartner J. Comparison of the EndoVac system to needle irrigation of root canals. J Endod 2007;33:611-615.

22. Metzger $Z$, Teperovich $E_{1}$ Cohen $R$, Zary $R$, Paqué $F$, Hülsmann $M$. The self-adjusting file (SAF). Part 3: removal of debris and smear layer - A scanning electron microscope study. J Endod. 2010;36:697-702.

23. Prado $M$, Simão RA, Gomes BP. Effect of different irrigation protocols on resin sealer bond strength to dentin. J Endod 2013;39:689-692.

24. Rasimick BJ, Nekich $M$, Hladek MM, Musikant BL, Deutsch AS Interaction between chlorhexidine digluconate and EDTA. J Endod 2008:34:1521-1523.

25. Prado $M$, Santos Júnior $H M$, Rezende $C M$, Pinto $A C$, Faria $R B$, Simão $R A$, et al. Interactions between irrigants commonly used in endodontic practice: a chemical analysis. J Endod. 2013;39:505-510.

Received January 30, 2017 Accepted May 2, 2017 